\title{
Cardiac Care Unit Admission Criteria for Suspected Acute Myocardial Infarction in New-Onset Atrial Fibrillation
}

\author{
HAROLD Z. FRIEDMAN, MD, NANCY WEBER-BORNSTEIN, MD, SCOTT F. DEBOE, BS, \\ and G.B. JOHN MANCINI, MD, FRCP(C)
}

\begin{abstract}
Management of new-onset atrial fibrillation (AF) varies between institutions and individual physicians. Because AF often occurs in elderly patients and is associated with coronary artery disease, patients presenting for the first time are often selected for admission to the coronary care unit to exclude the possibility of acute myocardial infarction (AMI). A review of 245 patients with AF admitted to an intensive care unit revealed 45 cases that were of new onset. AMI was diagnosed in $5(11 \%)$ on the basis of elevated serum creatine kinase-MB levels. Evaluation of $\mathbf{5 6}$ clinical variables available during initial assessment indicated that infarction patients could
\end{abstract}

be distinguished from others by the presence of left ventricular hypertrophy $(p<0.01)$, electrocardiographic evidence of old myocardial infarction ( $p$ $<0.01$ ), typical cardiac chest pain ( $p<0.01)$, and duration of cardiac symptoms less than 4 hours ( $p$ $<0.05$ ). The presence of 2 or more of these features identified all AMI patients and 7 others at high risk for serious cardiac complications. The findings indicate that new-onset AF in the absence of clinical predictors suggesting myocardial ischemia or AMI does not warrant routine admission to the coronary care unit.

(Am J Cardiol 1987;59:866-869) trial fibrillation (AF) is a common cardiac rhythm disturbance, estimated to be present in $0.4 \%$ of the general population. In persons older than 60 years, the prevalence increases to 2 to $4 \% .^{1,2}$ Despite its frequent occurrence, initial management of new-onset AF is controversial and varies among institutions and individual physicians. Because AF occurs often in elderly patients, is frequently associated with coronary artery disease and is considered to be a grave prognostic indicator during acute myocardial infarction (AMI), these patients are often selected for admission to the coronary care unit. ${ }^{1,3-5}$ In the emergency room, decision-making may be further influenced by presenting

From the Department of Internal Medicine, Division of Cardiology, Veterans Administration Medical Center, University of Michigan Medical School, Ann Arbor, Michigan. Manuscript received September 4, 1986; revised manuscript received October 31, 1986, accepted November 3, 1986.

Address for reprints: G.B. John Mancini, MD, Veterans Administration Medical Center, 2215 Fuller Road, Ann Arbor, Michigan 48105. symptoms that mimic those of an AMI. However, observations at this institution suggested that isolated new-onset AF was a rare mode of presentation of AMI. Furthermore, it was perceived that patients truly having AMI complicated by AF were distinguishable after initial evaluation from those with this arrhythmia and a low likelihood of AMI. If correct, patients with a low likelihood of AMI or other conditions would not need critical care services and therefore might be safely allocated to an intermediate or routine level of care for monitoring. ${ }^{6-8}$

\section{Methods}

All patients admitted to the cardiac and medical intensive care units at the University of Michigan Medical Center between January 1982 and November 1984 with the diagnosis of AF were studied. At that time it was general practice to admit all patients with new-onset AF. There were 245 patients identified and the medical records of 238 were available for evaluation. All patients who had a history of AF, had AF subsequent to admission, or lacked proper electrocardiographic documentation were excluded. After re- 
viewing the emergency room and the admitting and intensive care unit records, 45 cases of new-onset AF were identified.

Data were collected from the admitting physicians' notes, which included a thorough history, medical chart review, physical examination and laboratory flow sheet. The following information was retrieved: presence or absence of cardiac symptoms including quality and duration of any chest pains or palpitations, history of cardiac disease, blood pressure, average heart rate, estimated jugular venous pressure, results of pulmonary and cardiac auscultation, and presence or absence of peripheral edema. The term typical chest pain was used to characterize the following descriptions: substernal or precordial discomfort, and radiation of pain or pressure to the arms, jaw or neck. Laboratory data included the serum creatine kinase and lactate dehydrogenase levels with isoenzyme analysis, serum electrolyte and glutamic oxaloacetic transaminase levels, complete blood count, initial electrocardiogram and chest x-ray report from the radiology department. Hypokalemia was considered significant when it was less than $3.0 \mathrm{mEq} /$ liter. $^{9}$ The electrocardiograms were examined for heart rate, arrhythmias and morphologic abnormalities. A diagnosis of remote myocardial infarction was based on the presence of previously documented pathologic $Q$ waves. Left ventricular hypertrophy was diagnosed by Sokolow's criteria. ${ }^{10}$ All electrocardiograms were interpreted using a standard format and were overread by 1 of 3 staff cardiologists.

AMI was diagnosed by a creatine kinase level of at least $100 \mathrm{IU} /$ liter with an MB-isoenzyme fraction more than $4 \%$ of the total. An acute "transmural" AMI was defined by the presence of new $Q$ waves or $1 \mathrm{~mm}$ or more of ST-segment elevation in 2 or more of the electrocardiographic leads. An acute "nontransmural" AMI fulfilled similar enzymatic criteria but presented with at least $1 \mathrm{~mm}$ of ST-segment depression and Twave inversion, without $Q$ waves, in 2 or more leads. ${ }^{11}$

After chart review, missing data were retrieved by direct questioning of the primary care physicians, the patient, the patient's family or the family physician.

For data analysis, the patient population was categorized into those with and those without AMI. Fifty-six variables for each patient were assessed for dependence with AMI by use of chi-square analysis. Features found to be significant by this analysis were reassessed by a Fisher's exact probability test of association. Findings were considered significant when $p$ $<0.05$.

\section{Results}

Forty-five of the 245 patients admitted to a medical intensive care unit with AF had new-onset AF. AMI was diagnosed on the basis of creatine kinase-MB isoenzyme elevations in 5 cases $(11 \%)$. In 32 patients $(71 \%)$ AMI was ruled out in the intensive care unit, and 8 were initially started on a "rule out AMI" protocol in the emergency room, which was later canceled by the coronary care unit physicians. Positive MB lev-
TABLE I Presenting Cardiac Symptoms of Patients with NewOnset Atrial Fibrillation

\begin{tabular}{|c|c|c|c|}
\hline \multirow[b]{2}{*}{ Symptom } & \multicolumn{2}{|c|}{ Acute Myocardial Infarction } & \multirow[b]{2}{*}{ Significance } \\
\hline & $\begin{array}{l}+ \\
(n=5)\end{array}$ & $\begin{array}{c}0 \\
(n=40)\end{array}$ & \\
\hline Syncope & 0 & 0 & NS \\
\hline Dizziness & 0 & $7 / 40$ & NS \\
\hline Diaphoresis & $3 / 5$ & $10 / 40$ & NS \\
\hline Nausea/emesis & $2 / 5$ & $12 / 40$ & NS \\
\hline Palpitation & $2 / 5$ & $22 / 40$ & NS \\
\hline Dyspnea & $3 / 5$ & $22 / 40$ & NS \\
\hline Fatigue & 0 & $11 / 40$ & NS \\
\hline \multicolumn{4}{|l|}{ Chest pain } \\
\hline Typical & $4 / 5$ & $9 / 40$ & $p<0.01$ \\
\hline Atypical & 0 & $6 / 40$ & NS \\
\hline None & 0 & $22 / 40$ & NS \\
\hline Unknown & $1 / 5$ & 0 & NS \\
\hline \multicolumn{4}{|l|}{ Pain duration (hr) } \\
\hline$\leq 2$ & $3 / 4$ & $7 / 40$ & $p<0.01$ \\
\hline $2-4$ & $1 / 4$ & $4 / 40$ & $p<0.05$ \\
\hline $4-12$ & 0 & $4 / 40$ & NS \\
\hline $12-24$ & 0 & $1 / 40$ & NS \\
\hline$\geq 24$ & 0 & $20 / 40$ & NS \\
\hline
\end{tabular}

NS $\mp$ not significant; $+=$ positive results; $0=$ negative results

els were not present in these 8 patients and none was discharged with an electrocardiographic diagnosis of AMI.

Mean age of the 45 patients was $68 \pm 12$ years; $64 \%$ were men, $36 \%$ women; $7 \%$ were black. Preexisting cardiovascular disease was noted in 25 patients $(56 \%)$. Of those with cardiac disease, $12(48 \%)$ had coronary artery disease, $6(24 \%)$ had hypertensive heart disease, $4(16 \%)$ had cardiomyopathy and 1 patient each had pericarditis, mitral valve prolapse and rheumatic valvular disease. Nine patients were receiving digoxin for previously diagnosed heart failure or cardiomyopathy and none was receiving a type I antiarrhythmic agent.

Toxic or metabolic abnormalities were contributory factors in 3 cases $(7 \%), 11(24 \%)$ were classified as idiopathic $\mathrm{AF}$, and in $3(7 \%)$ a conclusive diagnosis was not made before discharge. A history of significant alcohol consumption before admission was recorded in 7 patients $(16 \%)$. Chronic lung disease was diagnosed in 8 patients $(18 \%)$ and $16(36 \%)$ smoked. Six patients had diabetes mellitus.

The presenting symptoms are listed in Table I. Significant differences between patients with and without AMI were noted for a history of typical cardiac pain ( $p<0.01$ ) and duration of symptoms less than 4 hours $(p<0.05)$. There were no differences in the physical findings or medical history between the groups. Laboratory results obtained before coronary care unit admission were not significantly different except for a positive creatine kinase-MB result, required by definition. In 2 cases, however, an initial negative MB measurement was positive in 6 hours or less. Results from thyroid function testing were available in 40 of the 45 cases and indicated hyperthyroidism in 2 . Significant serum potassium depletion $(2.6 \mathrm{mEq} / \mathrm{liter}$ ) was noted in 1 diabetic patient. Admission digoxin 
TABLE II Initial Electrocardiographic Findings in Patients with New-Onset Atrial Fibrillation

\begin{tabular}{|c|c|c|c|}
\hline \multirow[b]{2}{*}{ Finding } & \multicolumn{2}{|c|}{ Acute Myocardial Infarction } & \multirow[b]{2}{*}{ Significance } \\
\hline & $\begin{array}{c}+ \\
(n=5)\end{array}$ & $\begin{array}{c}0 \\
(n=40)\end{array}$ & \\
\hline $\begin{array}{l}\text { Mean heart } \\
\text { rate (beats } / \mathrm{min} \text { ) }\end{array}$ & $147 \pm 25$ & $143 \pm 29$ & NS \\
\hline Old infarction & 3 & 4 & $p<0.01$ \\
\hline $\begin{array}{l}\text { Bundle branch } \\
\text { block }\end{array}$ & 0 & $\begin{array}{l}4 \text { Right } \\
2 \text { Left }\end{array}$ & NS \\
\hline $\begin{array}{l}\text { Left ventricular } \\
\text { hypertrophy }\end{array}$ & 3 & 2 & $\mathrm{p}<0.01$ \\
\hline \multicolumn{4}{|l|}{$\begin{array}{c}\text { Primary ST-T } \\
\text { changes }\end{array}$} \\
\hline$>1 \mathrm{~mm}$ elevation & 0 & 0 & NS \\
\hline $\begin{array}{l}>1 \mathrm{~mm} \text { depression } \\
\text { or T-wave } \\
\text { inversion }\end{array}$ & 4 & 9 & NS \\
\hline $\begin{array}{l}\text { Nonspecific ST-T } \\
\text { abnormality }\end{array}$ & 1 & 15 & NS \\
\hline
\end{tabular}

NS $=$ not significant.

levels were not measured in 3 patients, not detectable in 3 and within therapeutic range $(0.5$ to $2.5 \mathrm{ng} / \mathrm{ml})$ in 3 .

The initial electrocardiographic abnormalities are listed in Table II. The presence of old $Q$ waves $(p$ $<0.01$ ) and left ventricular hypertrophy $(\mathrm{p}<0.01)$ were significantly greater in the AMI group. ST-segment elevation suggesting acute injury was not present on any electrocardiogram. Three patients had inferior and 2 had anterior nontransmural AMI. In each case the diagnosis was confirmed by a thallium scan or cardiac catheterization. Emergency electrical cardioversion was performed in 2 patients without AMI because of hypotension. There were no episodes of ventricular fibrillation or tachycardia during hospitalization. At discharge, 29 of the patients $(65 \%)$ were in sinus rhythm.

Presence of 2 or more of the 4 clinical features significantly associated with AMI were used to identify a group at risk for morbid cardiac events. All 5 patients with AMI were identified along with 7 others. In this group, 10 patients had no life-threatening events, 1 had mild heart failure and 1 died from cardiogenic shock. None of the 33 low-risk patients had a complication requiring acute intervention except for 1 patient, who received immediate cardioversion but was then discharged the next day. In the low-risk group there were 3 late deaths due to progressive pulmonary disease.

\section{Discussion}

Because coronary artery disease is associated with development of AF, AMI is often suspected by those caring for patients with this arrhythmia presenting for the first time. ${ }^{5}$ The findings of this analysis suggest that this concern, which has led some physicians to a policy of routine admission to the coronary care unit, can be limited to a subset of these patients. ${ }^{12,13}$

Eleven percent of patients presenting to the emergency room with symptoms of new-onset AF were

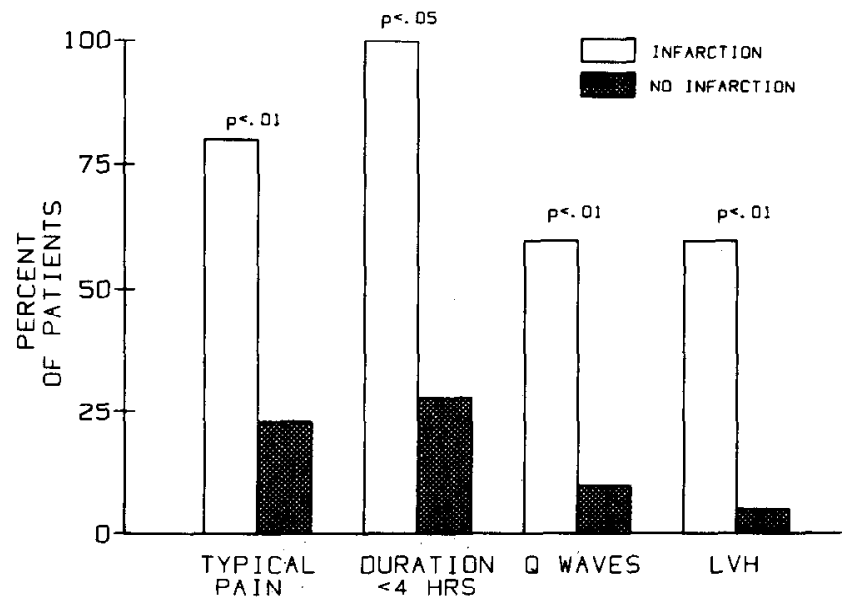

FIGURE 1. Percent of patients with clinical features found to be significantly different between patlents with and without infarction. LVH = left ventricular hypertrophy.

found to have evidence of an AMI. Based on 56 clinical variables available during the initial emergency room evaluation, patients with AMI were distinguishable from others by the presence of (1) left ventricular hypertrophy; (2) electrocardiographic evidence of an old myocardial infarction, (3) typical cardiac chest pain, and (4) duration of cardiac symptoms less than 4 hours (Fig. 1). Furthermore, the presence of any 2 of the 4 variables defined a high-risk subpopulation that included all of the patients with and only 7 of those without an AMI, suggesting that the admission rate to the intensive care unit could have been decreased by almost $75 \%$.

Severe pain suggesting acute myocardial ischemia or infarction was described by all patients with documented AMI who could give a history (1 patient was obtunded). In contrast, $70 \%$ of the patients in the group without AMI lacked typical cardiac symptoms. However, diabetics may be at increased risk for $A F$ and silent AMI; therefore, a high index of suspicion should be maintained during their evaluation. ${ }^{14}$

Electrocardiographic evidence of old myocardial infarction was significantly greater in the AMI group. Previous infarction markedly increases the likelihood of significant multivessel coronary disease, which would predispose a patient to ischemia and AMI with the onset of $A F$ and rapid ventricular rates. ${ }^{15}$ Left ventricular hypertrophy, present in all the AMI patients, increases the basal metabolic demands of the left ventricle, reduces blood flow per gram of myocardial tissue, and reduces the coronary flow reserve. ${ }^{16}$ With the onset of $\mathrm{AF}$, additional elevation of myocardial metabolic requirements may exceed the coronary flow reserve and result in severe myocardial ischemia and AMI.

The presence of 2 or more of the 4 clinical features significantly associated with AMI identified a highrisk group including all patients with AMI and early, life-threatening, cardiac complications. Other investigators have also recognized the uncertainty surround- 
ing emergency room triage decisions in patients with AF. ${ }^{12,17}$ Thibault observed that a benign hospital course was predicted by young age, a history of alcohol abuse, hypertension (without secondary hypertrophy) and presence of a primary cause for the tachyarrhythmia. Conversely, those in whom critical problems developed were older, female, and had ischemic electrocardiographic changes, chest pain or heart failure. ${ }^{17}$

The similarity between predictors of cardiac complications identified in other emergency room populations with chest pain and this study indicates that the traditional indicators of myocardial ischemia are reliably present in those with new-onset AF. A predictive equation applied by Pozen et $\mathrm{al}^{18}$ to identify AMI patients relied on clinical data that included the presence of chest pain, ST-segment depression, or elevation with or without $\mathrm{T}$-wave abnormalities, and a history of AMI. Similarly, Mulley et al ${ }^{19}$ stratified patient risk using total creatine kinase, ST-segment elevation, heart failure, ventricular ectopy, hypotension or recurrent chest pain within 24 hours. Thus, new-onset AF should not be unduly weighed in the decision to admit a patient to the coronary care unit.

The findings indicate that new-onset $\mathrm{AF}$ in the absence of clinical predictors suggesting myocardial ischemia or AMI does not warrant routine coronary care unit admission. Prospective application of the criteria found in this study is required to determine their usefulness in generating efficient use of intensive care resources.

\section{References}

1. Kannel WB, Abbott RD, Savage PD, McNamara PM. Epidemiologic features of chronic atrial fibrillation. N Engl / Med 1982;306:1018-1022.
2. Gajewski J, Singer RB. Mortality in an insured population with atrial fibrillation. JAMA 1981:245:1540-1544.

3. Rajala SA, Geiger UKM, Haavisto MV, Kaltiala KS, Mattila KJ. Electrocardiogram, clinicul findings and chest $\mathrm{x}$-ruy in persons aged 85 yeurs ur older. Am I Cardiol 1985;55:1175-1178.

4. Cristal N, Peterburg I, Szwarcberg I. Atrial fibrillation developing in the acute phase of myocardial infarction. Chest 1976;70:8-11.

5. Kannel WB, Abbott RD, Savage DD, McNamara PM. Coronary heart disease and atrial fibrillation: the Framingham Study. Am Heart J 1983; 106:389-396.

6. Fuchs R, Scheidt S. Improved criteria for admission to the cardiac care units. IAMA 1981;246:2037-2041.

7. Fineberg HV, Scadden D, Goldman L. Care of patients with a low probability of acute myocardial infarction. $N$ Engl I Med 1984;310:1301-1307.

8. McGregor M. Myocardial ischemia. Am I Med 1984;76:887-890.

9. Surawicz B. Relationship between electrocardiogram and electrolytes. Am Heart J 1967:73:814-834.

10. Sokolow $M$, Lyon TP. The ventricular complex in left ventricular hypertrophy as obtained by unipolar precordial and limb leads. Am Heart I 1949:37:161-186.

11. Rude RE, Poole WK, Muller JE, Turi Z, Rutherford J, Parker C, Roberts R, Raabe DS, Gold HK, Stone PH, Willerson JT, Braunwald E. Electrocardiographic and clinicul criteriu for recognition of acule myocardiul infarction based on analysis of 3,697 patients. Am I Cardiol 1983;52:936-942.

12. Lowenstein SR, Gabow PA, Cramer J, Olivia PB; Ratner. $K$. The role of alcohol in new-onsct atrial fibrillation. Arch Intern Med 1983:143:18821885 .

13. Rich E, Siebold C, Campion B. Alcohol related acute atrial fibrillation Arch Jntern Med 1985:145:830-833.

14. Bradley RF, Schonfeld A. Diminished pain in diabetic patients with acute myocardial infarction. Geriatrics 1962;17:322-326.

15. Betriu A, Castaner A, Sanz GA, Pare IC, Roig E, Coll S, Magrina I, Navarro-Lopez F. Angiographic findings one month after myocardial infarction: a prospective study of 259 survivors. Circulation 1982;65:10991105.

16. Hoffman JE. Maximal coronary flow and the concept of coronary vascular reserve. Girculation 1984;70:153-1599.

17. Brush JE, Brand DA, Acampora D, Chalmer B, Wackers F]. Use of the initial electrocardiogram to predict in-hospital complications of acute myocardial infarction. N Engl I Med 1985;312:1137-1141.

18. Pozen MW, D'Agostino RB, Selker HP, Sytrowski PA. Hood WD. A predictive instrument to improve coronary-care-unit admission practices in acute ischemic heart disease. $N$ Engl I Med 1984;310:1273-1278.

19. Mulley AG, Thibault GE, Hughes RA, Barnett GO, Reder VA, Sherman EL. The course of patients with suspected myocardial infarction. $N$ Engl' Med 1980:302:943-948. 